Research Artide

JOURNAL OF THE CAMEROON ACADEMY OF SCIENCES Vol. 14 No. 3 (JANUARY 2019)

\title{
REFUGEE HEALTH PROBLEMS IN THE CENTRAL AFRICAN SUB- REGION: THE ROLE OF TRADITIONAL MEDICINE
}

\section{Justine G Nzweundji and ${ }^{*}$ Gabriel A Agbor}

${ }^{1 *}$ Centre for Research on Medicinal Plants and Traditional Medicine, Institute of Medical Research and Medicinal Plants Studies, Cameroon P.O. Box: 13033, Yaoundé-Cameroon. Email: agogae@yahoo.fr; Phone: +237 677223674 Email: nzweundji@gmail.com; Phone: +237 93667518

*Corresponding author

ABSTRACT

This review focuses on the role that African Traditional Medicine can play in addressing the health problems of refugees in the central sub-region with focus on Cameroon. This paper is based on a review of literature on the influx of refugees and their well-being. Over 400000 refugees live in Cameroon particularly in the Far North (Nigerians) and in the Eastern (Central Africans Refugees) Regions of Cameroon. About 80 per cent of the refugees arriving in Cameroon suffer from serious ailments such as malaria, diarrhea, anemia and respiratory tract infections, while more than 20 per cent of children are severely malnourished. To curb these diseases UNHCR and NGOs provide medications to refugees which often arrive late; some of which at times expire in stock or some different distribution centres run out of stock. An aid could come from Traditional Medicine Practitioners who have been very effective in management of disease conditions in refugee camps in some countries in the world. The Cameroon Traditional Medicine if well-developed will do same to act as first-aid before the arrival of conventional medicine or complement western medicine to manage patients who do not accept western medicine because of cultural believes.

\section{Resumé}

Cette revue met l'accent sur le rôle que peut jouer la Médecine Traditionnelle africaine sur l'amélioration de la santé des refugiées dans la sous-région, en se focalisant sur le Cameroun. Cet article est basé sur une revue de la littérature de l'afflux des réfugiés et leur bien-être. Plus de 400000 réfugiées vivent au Cameroun, en particulier dans l'Extrême-Nord (Nigérians) et dans les régions de l’Est (Réfugiés centrafricains). Environ $80 \%$ des refugiés qui arrivent au Cameroun souffrent de maladies graves telles que le paludisme, la diarrhée, l'anémie et les infections des voies respiratoires, tandis que $20 \%$ des enfants souffrent de malnutrition grave. Pour lutter contre ces maladies, le HCR et les ONG fournissent aux réfugiés des médicaments qui malheureusement arrivent parfois en retard, certains d'entre eux expirent en stock et certains centres de distribution sont à court de stocks. Les praticiens de la Médecine Traditionnelle qui ont l'expérience de la gestion des maladies dans les camps des réfugiés de par le monde pourraient apporter une aide précieuse. La Médecine Traditionnelle camerounaise, si elle est bien développée fera pareil pour les soins de premiers secours avant l'arrivée de la Médecine Conventionnelle ou complètera la médecine occidentale pour traiter les patients refusent cette dernière pour des raisons culturelles.

\section{Received: 14/ 08/ 2018}

Accepted: 24/ 12/ 2018

D0 I: https:/ / dx.doi.org/ 10.4314/ jcas.v14i3.3

(C) The Authors. This work is licensed under the Creative Commons Attribution 4.0 International Licence. 


\section{INTRODUCTION}

The word "refugee" is contained in the 1951 United Nations Convention and its 1967 Protocol relating to the Status of Refugees. This text defined a refugee as an individual who: "owing to a well-founded fear of being persecuted for reasons of race, religion, nationality, membership of a particular social group or political opinion, is outside the country of his nationality, and is unable or unwilling to avail himself/ herself of the protection of that country (Russell, 2002) " This definition so-called "statutory refugees" excluded mass flight from war. Hence in 1969, the O rganization for African Unity (1969 convention) expanded the definition of refugees to include every person who - "owing to external aggression, occupation, foreign domination, or events seriously disturbing the public order is compelled to leave, to seek refuge in another place outside his country of origin or nationality." Massive human rights violations was added to this definition by a group of Latin American states and was adopted by the Cartagena Declaration in 1984 (Russell, 2002).

From time immemorial displacement has been part and parcel of mankind. Conflicts, natural or man-made disasters as well as persecutions of political, socio-cultural and religious conflicts have been the major causes of human displacements within and across boundaries. This has been an awakening in the African content since after the Cold war witnessing more of intrastate violence than the classical interstate conflicts. Whenever there is an outbreak of violence scores of vulnerable persons are forced to move towards politically calm and peaceful countries for refuge. The Central African SubRegion has proven to be the breeding grown with the most uncontrollable refugee catastrophe in the African continent (Mbuli, 2013). Insecurity, violence, torture, sexual violence, extrajudicial executions, enforced disappearance and widespread human rights violations by armed elements against the population in the Central African Republic (CAR) caused an influx of refugees into neighboring countries such as Chad, Cameroon, the D emocratic Republic of the Congo (DRC) and the Republic of the Congo in 2015. All four countries shared the burden of Central Africa Republic and registered over 441,000 refugees as of $O$ ctober 2015 (Diagne et al., 2016).

Often before refugees arrives a safe haven, they spent days, weeks, months and even years in the bush, forests or even highway without access to quality water, food and health care. An earlier report estimated 80 per cent of such population to be exposed to insect bites such as mosquitos, flies etc resulting to malaria, filarial and river blindness. Other diseases plaguing refugees include diarrhea, anemia, typhoid fever and respiratory infections, while more than 20 per cent of children are severely malnourished (Djerassem et al., 2016). None Governmental O rganizations (NGOs) work in collaboration with UNHCR to provide health coverage for refugees. However, this has not been 100 percent successful because Traditional Medicine has not been included as an option. Most refugees and displaced populations come from remote areas where they still depend on Traditional Medicine to address public health needs. Some have never had a medical examination or taken modern medicine. Hence afraid of being introduced to new approaches they are not used too. Many will feel safer being treated by their Traditional Medicine than the modern medicine.

The post-independence period of Cameroon has been relatively calm making it a major pole of attraction for refugees and displaced persons in Africa (Mbuli, 2013). Conflicts in both Federal Republic of Nigeria and Central African Republic (C.A.R.) have displaced thousands of people into Cameroon (Engdahl, 2016). As such, the 
capacities of health centers to guarantee quality health care for refugees and host communities in Cameroon need to be strengthened, as well as the supply and management system of medicines (Mbuli, 2013).

The present review presents the health needs of refugees in Cameroon and proposes the use of Traditional Medicine to compliment the Western Medicine for effective management of the health situation of refugees.

\section{METHODOLOGY}

The collection of information was done through bibliography research. We searched for articles, in G oogle scholar using keyword and combination of keywords. Those words included "refugees", "refugee health", "use of traditional medicine in refugee health", "health burden in refugee camps", "refugees Cameroon health", "health intervention strategies in refugee camps", "refugees HIV $\neg$ AID S", "Internal Displaced Persons", "Traditional Medicine in Cameroon", "UNHCR refugees". We also sought for report on UNHCR website. We then collaborate with personnel of Trauma Center Cameroon, an organization recognize by UNHCR to provide psychological, financial, material and health care of refugees in Cameroon. They confirm and provide us the update information and some practical cases.

\section{REFUGEES IN CAMEROON}

Intrastate conflicts in Africa caused about 24.2 million refugees and displaced persons in the central Africa region as of 2017 (UNHCR, 2018). Cameroon, an adherent to both international (Geneva 1951 and 1967) and continental (OAU) conventions and protocols on refugees has been a hospitable host to thousands of refugees and displaced persons from across the continent. Human insecurity has also been noted as an impact of the presence of refugees in Cameroon. In 1980 the influx of Chadian refugees, increased the population of Kousseri from 10.000 to an approximate 230. 000 inhabitants (Bandoleo, 1980). The aid packages became insufficient and foreign donors and other international bodies were requested to increase their support to the government of Cameroon. The influx of refugee also saw an increase in epidemic diseases, measles, cholera and typhoid fever in the Kousseri region and a great shortage in vaccines and medicines (Ndembiyembe, 1980). Hospitals were packed to capacity and the local inhabitants of Kousseri became affected by different epidemic diseases originating from the refugee camps (Ndembiyembe, 1980). A similar situation repeated itself during the February 2008 refugee influx in the North of Cameroon. Today the situation remains the same with major influx of refugee from two neighboring countries basically Central African Republic (CAR) and Federal Republic of Nigeria. As of 2008, the CAR refugee in Cameroon numbered approximately 70,000. The additional UNHCR registration of more than 18,250 additional refugees from the Central African Republic in 2009 raised the total number of refugees in Cameroon's East and Adamaoua regions (the two poorest regions in the country) to 80,880 (UNHCR Global Report 2009). 


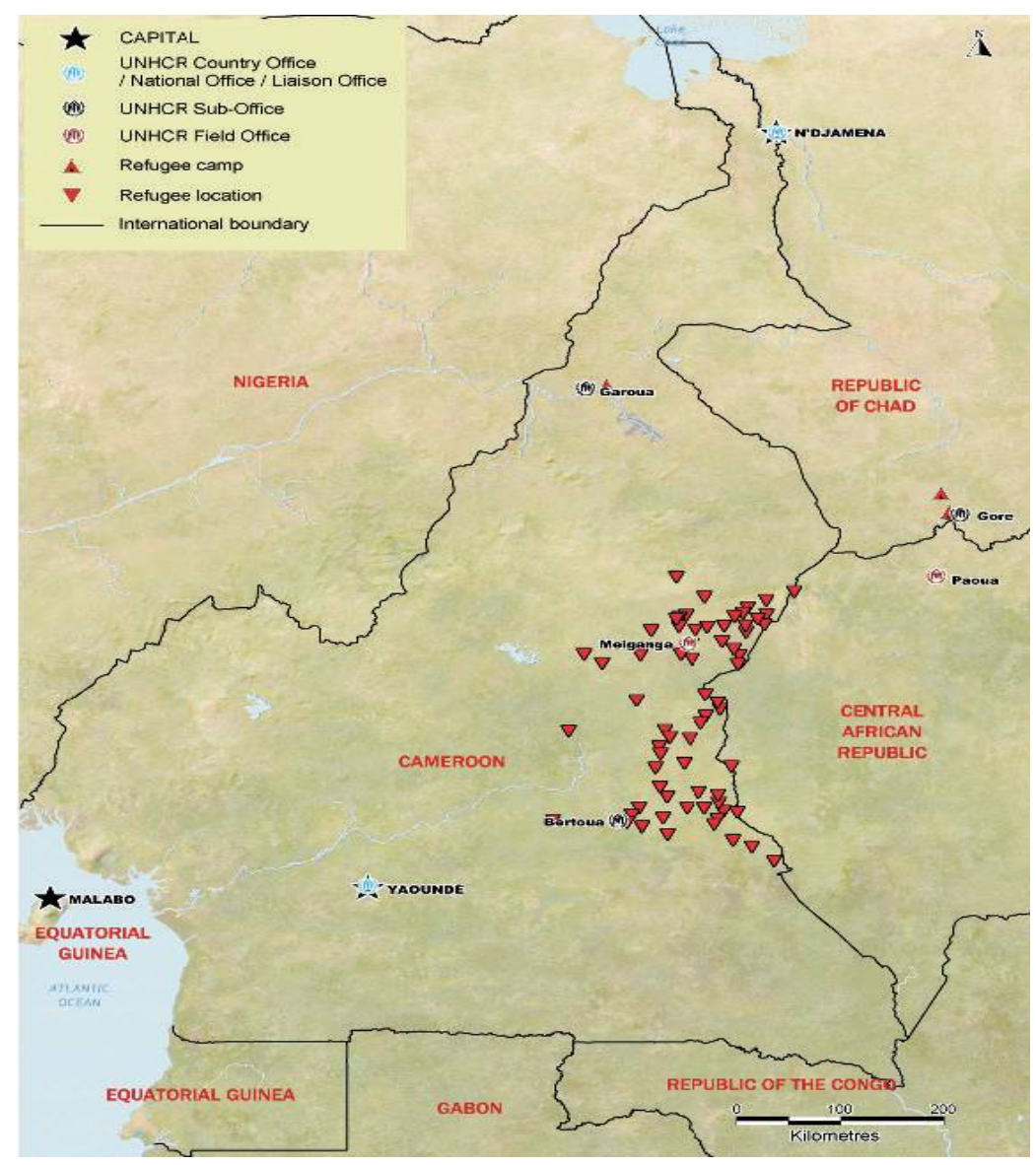

Figure 1: Refugee camps as of 2008 (source: UNHCR G lobal Report 2009)

June 2016 registered a total of 274,090 C.A.R. refugees in Cameroon distributed as follows: 180,485 in the Eastern Region (in and out of the sites); 71,506 in the Adamaoua Region (in and out of the sites); 14,945 in the urban areas, and 7,154 in the Northern Region (in villages) (Djerassem, 2016). The CAR refugees are hosted in several sites across the East (Mbile, Lolo, Timangolo, Ngarisingo and Gado Badzere) and Adamoua (Ngam and Borgop) regions (Figure 2). Nigerian refugees crossing the border into the Extreme North region are gathered in the Minawaou camp. In an earlier report 65,620 Nigerian refugees were registered in the Far North region (of which 56,921 are registered at Minawao camp) and 190,591 Internally Displaced Persons (Figure 2). A convention to provide health assistance to refugees living in Cameroon has been signed between the Government of Cameroon and the United Nations High Commission for Refugees. Also Cameroon adopted a law for refugee protections in July 2005 (UNHCR, 2015). 


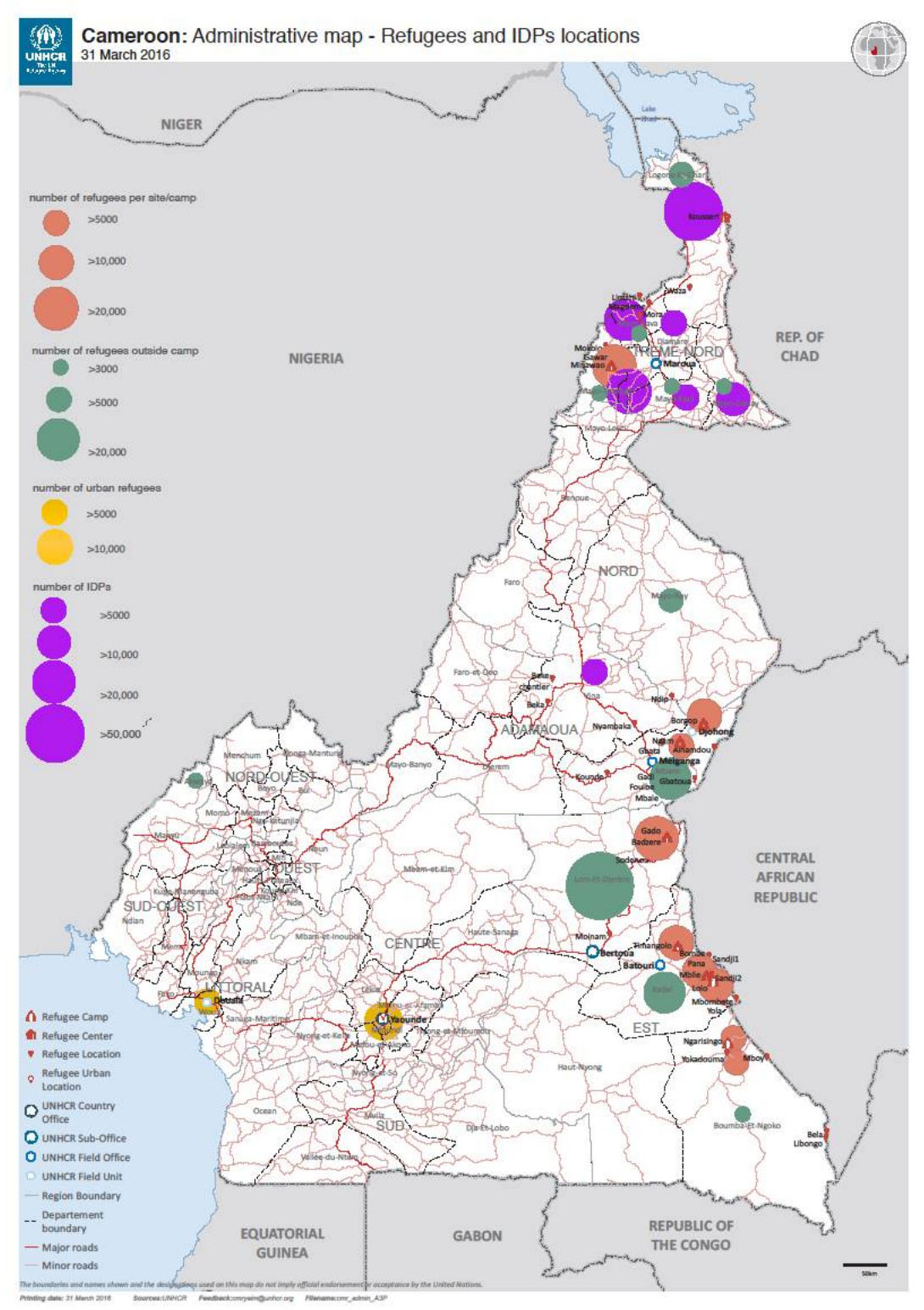

Figure 2: Cameroon administrative map - Refugees and Internally D isplaced Persons locations. (Source: UNHCR, 2016)

HEALTH PROBLEMSOF REFUGEESIN

\section{CAMEROON}

Health is the state of wellbeing of an individual and is the fundamental objective of socioeconomic development (Grosse and Harkavy, 1980). A significant reduction in the morbidity and mortality will directly boast economic development. Hence the Government has the obligation to maintain its population in good health. Approximately 40 percent of Cameroon population lives below the poverty line while the human development indicators also remain low
(WFP, 2018) with strong regional dimension concentrated in North, Far North, Adamawa and East regions. And these are the areas exposed to refugees. The Northern Regions of Cameroon located in the Sahel are the areas deprived the most because the communities have suffered years of continued natural disasters and very poor harvests, with inadequate means to resist the continuous cycle of shocks. In 2015, food insecurity rate was alarming: In the four poorest regions 2.3 million people were food insecure of whom over 60 percent were located in the Far 
North, where 1 in 3 people are moderately or severely food insecure. According to FAO, Food insecure is a situation that exists when people lack secure access to sufficient amounts of safe and nutritious food for normal growth and development and an active and healthy life (FAO, 1983). Similarly, the Standardized Monitoring and Assessment of Relief and Transitions (SMART) survey conducted by UNICEF in 2015 indicates an increase in malnutrition rates in the Far North of about $7 \%$ in 2014 to $11.7 \%$ in 2015 (Engdahl, 2016).

In taking care of Refugee health it is important to consider the distinctions between migration and resettlement. D uring pre-migration a refugee is exposed to infectious and parasitic diseases, physical and psychological trauma. Refugee health is also important during post-migration and resettlement during which increasing susceptibility to chronic diseases, problems and stressors of resettlement (racism, unemployment, crime, etc.) sets in (Burgess, 2004). O ther important Refugee health complications in developing countries include pregnancy/ childbirth complications among women of reproductive age. More than 60 percent of the world's maternal deaths occur in 10 countries, nine of which are experiencing or emerging from armed conflict (WHO et al., 2010).

Studies carried out by the Regional delegations of the East and Adamauoa of Cameroon with the collaboration of WHO on health profile of refugees showed that a serious gap still exist despite the government efforts. Moreover, only 1.8 percent of health staff of emergency area are trained to support mental health and psychosocial problems (Djerassem, 2016). Since 2013, 1206 patients have been consulted at medical Service of Trauma Center. Twenty diseases were identified, including more than $50 \%$ of prevalence of malaria and typhoid fever followed by intestinal parasitosis, sexually transmitted infections and pneumo-broncopathy (Table 1). Table 1 showed reports on patients with more than one health complaints (Trauma Center Cameroon, 2016). 
Table 1 : Prevalence of diseases among refugees in Cameroon between 2013 to 2016 (Trauma Center Cameroon, 2016)

\begin{tabular}{|c|c|c|c|c|c|c|c|c|}
\hline \multirow{2}{*}{$\begin{array}{l}\text { Year } \\
\text { Number }\end{array}$} & & \multicolumn{2}{|c|}{2016} & \multicolumn{2}{|c|}{2015} & \multicolumn{3}{|c|}{2014} \\
\hline & & 248 & $\%$ & 297 & $\%$ & 354 & $\%$ & 307 \\
\hline \multirow{24}{*}{ Diseases } & Malaria & 145 & 58,5 & 181 & 60,9 & 166 & 46,9 & 123 \\
\hline & Typhoid fever & 158 & 63,7 & 85 & 28,6 & 103 & 29,1 & 55 \\
\hline & Intestinal Parasitosis & 32 & 12,9 & 33 & 11,1 & 26 & 7,3 & 37 \\
\hline & Hemiparasites & 9 & 3,6 & & 0,0 & 6 & 1,7 & \\
\hline & Respiratory infection & 5 & 2,0 & 2 & 0,7 & 14 & 4,0 & 9 \\
\hline & Pneumo-broncopathy & 17 & 6,9 & 3 & 1,0 & 37 & 10,5 & 11 \\
\hline & Gastroentérite & 9 & 3,6 & & 0,0 & 29 & 8,2 & \\
\hline & Amygdalite & 2 & 0,8 & 8 & 2,7 & 6 & 1,7 & 2 \\
\hline & Rhino-pharyngite & 11 & 4,4 & 2 & 0,7 & 4 & 1,1 & 6 \\
\hline & Otite & 7 & 2,8 & & 0,0 & 2 & 0,6 & 4 \\
\hline & Abscess & & 0,0 & 1 & 0,3 & 3 & 0,8 & \\
\hline & $\begin{array}{l}\text { Sexually transmitted } \\
\text { infections (STIs) }\end{array}$ & 23 & 9,3 & 18 & 6,1 & 37 & 10,5 & 12 \\
\hline & Appendicite & & 0,0 & 5 & 1,7 & 3 & 0,8 & 4 \\
\hline & Hypertension & & 0,0 & 4 & 1,3 & 6 & 1,7 & \\
\hline & Rhumatism & 2 & 0,8 & 7 & 2,4 & 8 & 2,3 & 2 \\
\hline & Tooth decay & 6 & 2,4 & 7 & 2,4 & 15 & 4,2 & 4 \\
\hline & Other tooth problems & 5 & 2,0 & 3 & 1,0 & & 0,0 & 2 \\
\hline & $\begin{array}{l}\text { Ophtalmological } \\
\text { problems }\end{array}$ & 14 & 5,6 & 8 & 2,7 & 23 & 6,5 & 5 \\
\hline & $\begin{array}{l}\text { Dermatological } \\
\text { problems }\end{array}$ & & 0,0 & & 0,0 & 12 & 3,4 & 3 \\
\hline & Constipation & 2 & 0,8 & 3 & 1,0 & 9 & 2,5 & \\
\hline & Food intoxication & 3 & 1,2 & & 0,0 & 1 & 0,3 & \\
\hline & Mump & & 0,0 & 2 & 0,7 & 2 & 0,6 & 4 \\
\hline & Rectal incontinence & 1 & 0,4 & & 0,0 & 1 & 0,3 & \\
\hline & Pain & 12 & 4,8 & 6 & 2,0 & 16 & 4,5 & 5 \\
\hline
\end{tabular}

\section{ACCESS OF WESTERN MEDICATION TO REFUGEES}

Refugees are mostly hosted in camps and all receive basic health care and may be referred to hospitals outside the camp when necessary. NonGovernmental Organizations (NGOs) work in collaboration with UNHCR to provide health coverage for refugees and maintain the main health indicators within acceptable standards. In 2009 the refugee population was low and UNHCR in collaboration with 42 integrated health centres and seven district hospitals provided medical care and referral for refugees from CAR in the Adamawa and East Region
(UNHCR, 2009). Full health care is given to refugees leaving in camps, and partially for those of urban areas. However, full health care is given to all children refugees of zero to 5 years old and all pregnant women refugees' weather living in camps or urban areas. Also critical cases of refugees of urban areas can receive full support from UNHRC depending on the decisions of their panels.

The growing number of refugees in Cameroon presents enormous challenges to western biomedical practice. Some of the reasons include inadequate medications supply, lack of medication for specific disease needs, hence making it 
impossible to provide full care for all the refugees. Stock shortage leads to distribution of available medication irrespective of patients' disease conditions. Most often ibuprofen, paracetamol or multivitamin are given to patients suffering from malaria, headache, influenza, stomachache and typhoid. Some of these patients end up dying before the arrival of new batch of medications since they do not have any financial means to buy medication or alternative source for medication. There are also difficulties in crosscultural communication, disparate health practice beliefs, and limited cultural awareness on the part of the provider (personal interviews).

\section{DEVELOPMENT OF TRADITIONAL MEDICINE IN CAMEROON}

Traditional Medicine has earlier been defined as the sum total of all the knowledge and practices, whether explicable or not, used in diagnosis, prevention and elimination of physical, mental or social imbalance and relying exclusively on practical experience and observation handed down from generation to generation, whether verbally or in writing. (WHO, 1976). It was also decided that all medicines are modern as long as it is satisfactorily directed towards the common goal of providing health care, despite the setting in time, place and culture (WHO, 1976). Hence the essential difference among the various system of medicine arises not from the difference in goals or effect, but rather from the cultures of the people who practice the different systems. However, medicine as practiced in the industrialized countries, has kept abreast of scientific and technological innovations to the extent that it is often exclusively referred to as modern unlike the medicine practiced in developing countries now described as traditional. Traditional Medicine is a common form of primary health care in many developing countries, with up to $80 \%$ of African population relying on traditional medicine for primary care (Bodeker et al., 2005). According to WHO, this is due to the fact that over one third of populations in developing countries lack access to essential medicine as in many remote villages and rural areas in the world hence relying solely on Traditional Medicine for primary health care (Bodeker et al., 2012). Indeed, many Traditional Medicine therapies are more affordable, locally available, culturally familiar, and in some cases safer than Western pharmaceuticals, making traditional medicine a valuable resource for public health development worldwide (Bodeker et al., 2006).

Cameroon has a significant diversity of flora and fauna which includes; the Sahelian, Sudan, humid tropical forest, afro mountains, coastal and mountain eco-regions and contributes about 90\% of the African ecosystems and ranked 5th in Africa after The Republic of Congo, South Africa, Madagascar and Tanzania (Cunningham, 1993). This rich biological biodiversity is associated with the diversity of the ethnic groups in which each contributes a unique ethno pharmacopoeia and to Cameroon a national therapeutic patrimony, which is the richest in Africa (Houghton, 1995; Nkongmeneck et al., 2007).

Seven points have been laid down to develop Traditional Medicine in Cameroon: 1-D rafting a national policy to regulate the use and integration of Traditional Medicine into national health care systems in line with the provisions of the WHO strategies on Traditional Medicines; 2- Develop national policies on the evaluation and regulation of Traditional Medicine practices; 3- Establish a regulatory mechanism to control the safety, efficacy and quality of products and practice of Traditional Medicine; 4-Create public awareness on safe and effective Traditional Medicine therapies; 5-Ensure conservation of medicinal plants to ensure their sustainable use; 6-Ensure availability and affordability of Traditional Medicine including essential herbal medicines; 7- 
Document traditional medicines and remedies (Nkuinkeu et al., 2007; Jiofack et al., 2008).

A lot of effort is ongoing in Cameroon today to improve on the relationship between conventional medicine and Traditional Medicine. It all started in 1979 when a unit of Traditional Medicine was created within the Department of Health. And in 1981, law $n^{\circ} 81 / 12$ of 27 November 1981 was enacted to lay down joint strategy and method to effectively integrate Traditional Medicine into the national health plan. This had to oversee the implementation of a program on Traditional Medicine in conjunction with some neighboring countries to Cameroon. Still in 1981, a Traditional Medicine Unit was set up in the Yaoundé Central Hospital, followed by the creation of a Community Health and Traditional Medicine Service with a Unit in charge of Traditional Medicine in 1989. In 1090 law n ${ }^{\circ}$ 90/ 053 of 19 D ecember 1990 on Freedom of Association led to the creation of several Associations of Traditional Healers all over Cameroon. In 2002, a service for Traditional Medicine was established in the Ministry of Health, including a unit for ethics and deontology and another for legislation and control. Still in 2002 there was also a scientific sub-department to promote medicinal plants in the Ministry of Public Health. Earlier in 1974, the Institute of Medical Research and the Medicinal Plant Studies (commonly known by its French acronym: IMPM) was created by decree $\mathrm{n}^{\circ} 74 / 888$ of 6 June 1974 , and reorganized into a public establishment for scientific research by decree $n^{\circ} 93 / 215$ of 4 August 1993. O ne of the missions of the institute is to create conditions for the optimization of the impact of our local pharmacopeia and Traditional Medicine on the health of Cameroonians. IMPM has as mission to valorize the use of medicinal plants and traditional medicine to improve the health concerns of Cameroonians through one of its operational Centre - The Centre for Medicinal Plants and Traditional Medicine Research (French acronym: CRPMT). (Fokunang et al., 2011; Asongayni, 2011). IMPM collaborates with the Ministry of Public Health for the regularization of the use of Traditional Medicine in Cameroon and organizes capacity building workshops for traditional healers to improve on the hygienic conditions and presentation of their traditional remedies annually. IMPM also renders services to traditional health practitioners in evaluating the toxicity and efficacy levels of some of their herbal preparations.

Despite the entire program in progress for the development of the Traditional Medicine sector numerous constraints still exist and can summarized as follows: There is lack of institutional support for production and distribution of key species for cultivation. The low prices paid for traditional medicinal plants by herbal medicine traders and urban herbalists is a challenge; The lack of appropriate technology for post-harvest and pre-processing purposes adapted productively and effectively; Insufficient documentation and scientific experimentation for verification and validation of the Herbalist's claims; Lack of preservation of medicinal extracts or products for extended shelf life (MINSANTE, 2007; Jiofack et al., 2009. Also the absence of a legal framework and official recognition of Traditional Medicine by Western medicine practitioners hinders collaboration between the two. Traditional Health Practitioners are not accepted but barely tolerated because of the decree that has created a harmonization of the primary health care involving all stake holders. There are no laws guiding the Traditional Medicine practice in Cameroon. The Traditional Medicine sector is volatile, isolated, uncensored and open to all, consequently breeding quacks or the so called charlatans. However, there are some drawbacks of traditional medicine, which include incorrect diagnosis, improper dosage, and low hygiene standards, the secrecy of some healing 
methods and the absence of written records about the patients (LeBeau, 1998; Teklehaymanot, 2009). The dressing code of Traditional Health Practitioners is also a call for concern.

\section{INTEGRATION OF TRADITIONAL MEDICINE IN REFUGEES HEALTH CARE}

Today there are over 100 humanitarian organizations involved in delivering health and welfare services to refugees and migrants (UNHCR, 2004). The emergency approach taken by many of these humanitarian organizations is vital during the initial phase of most forced migration situations, and such interventions save thousands of refugees' and migrants' lives each year (Cookson, 1998; Hansch and Burkholder, 1996). According to traditional medicine theory, health is believed to be related to interactions between the physical body, spiritual elements, and the natural world (Bodeker, 2012). However, in order to facilitate local cooperation and compliance, as many of these situations such as border, issues of culture, identity, and traditional practice become important. Evidence shows that local leaders and traditional health practitioners play a valuable role in providing psychosocial and maternal health support within refugee communities and that neglect of traditional practices can contribute to or exacerbate primary, gender-based, and psychosocial health concerns (Hinton et al., 2003).

Conversely, incorporating traditional health knowledge into health and rehabilitation programs can improve refugees' mental and physical health (Singer and Adams, 2011).

Cultural sensitivity is often as crucial as competent interpretation in cross-cultural medical treatment. Hence, health providers must consider cultural factors when they take medical history and physical exam make inquire about traditional treatments practiced and assess care needs (Burgess, 2004). Many refugees seek out traditional or culturally familiar medicine through their local community. It is important for Medical doctors to be aware of herbal medicines that refugee clients may be taking. In Kakuma Refugee Camp, Kenya studies reported on the extent of Traditional Medicine use and the availability of common medicinal plants, with a vision to suggesting combined conservation and bioenterprise plans (Sachedina, 2003). Traditional Medicine has been implicated and continues to be appreciated and valued by more than one million Burmese refugees living in Thailand for many conditions, health service training and delivery (Bodeker et al., 2005). It has also been reported that East African refugees living in the United States have deep cultural, religious, and traditional health practices that determine their health behavior and influence their interactions with Western health care systems (Simmelink et al., 2013).

Many refugees come from countries, suburbs or underdeveloped area where traditional medicine is widely practiced, and may be expecting to access similar forms of health care in Cameroon. This can also provide affirmation of the patients' culture and healing traditions (Hiegel, 1994, Mollica et al., 2004, Bodeker et al, 2005). O ne of the factors identified by refugee that influences their utilization of mainstream health services is whether doctors accept and respect their traditional healing methods alongside orthodox medicine (Henderson and Kendall, 2011).

\section{CONCLUSION}

This paper presents the flow of refugees and their challenges, particularly health challenges. Refugees leaving in Cameroon come mostly from CAR, Tchad and Nigeria. There is also thousands of Internal Displaced Persons. According to health issues, more than $50 \%$ has malaria and 
typhoid fever. For HIV-AIDS, full health care is provided to refugee of urban areas, and available in hospital and partner structures of UNHCR. Regards to the importance and advantage of Traditional Medicine as availability, low cost, absence or low side effects, the Cameroon government trough recognized Institutions has the ability to disseminate and promote the use of Traditional Medicine to underprivileged populations.

\section{RECOMMENDATIONS}

In order to incorporate Traditional Medicine in the Health Care of Refugees in Cameroon, the following may be important:-

i.

Create a good and viable phyto-pharmaceutical industry in Cameroon;

ii.

Translate Traditional Medicine research into innovation by stepping up the already existing research funding to meet up with the Abudja declaration (Annual 2\% of G D P for Research and Innovation);

iii.

Establish Traditional Health Clinics in refugee camps

iv.

Establish collaboration between the refugee organizations and IMPM.

The collaboration with IMPM will have as objectives: a) to develop knowledge of local medical plants and to provide training for health workers and manuals for local families and communities. This will create knowledge and data base of locally available medicinal plants for use in managing common ailments, such as fevers, wounds, coughs, colds, diarrhea, typhoid etc; b) to investigate and understand traditional health knowledge and practices of local refugee populations; c) to offer opportunities for leaming and network development among traditional health practitioners along the Cameroonian border; and d) to document and create a traditional medicinal plant database with a view to training new practitioners and creating a family home herbal medicine book in the local languages.

\section{References}

Asongayni, T. (2011): Relationship between Conventional and Traditional Medicine in Cameroon. Health Sci. Dis. 12 (2) Editorial.

Bandoleo, H. (1980) : Réfugiés Tchandiens: situation alarmante à Kousseri, Cameroon Tribune, the National Bilingual Daily (1784) : 1.

Bodeker, G. and Neumann, C. (2012): Revitalization and Development of Karen Traditional Medicine for Sustainable Refugee Health Services at the Thai-Burma Border. Joumal of Immigrant \& Refuge Studes, 10:6-30.

Bodeker, G., Neumann, C., Ong, C. and Burford, G. (2006): Training. In G. Bodeker \& G. Burford (Eds.), London, England: Imperial College Press. Traditional, complementary \& alternative medicine: PublicHealth \& PdicyPespetivespp. 6181, London, England: Imperial College Press. .

Bodeker, G., Neumann, C., Lall, P. and Oo, Z. M. (2005): Traditional Medicine Use and Health worker Training in a Refugee Setting at the Thai-Burma Border. Jourmal of Refugee

Studies 18 (1): 76-99.

Burgess, A. (2004): Health Challenges for Refugees and Immigrants. Refugees Report (25):2. Cookson, S., Waldman, R., Gushulak, B., MacPherson, D., Burkle, F. Jr., Paquet, C., Kliewer, F. and Walker, P. (1998): Migrant and refugee health. Emaging Infetious Diseses (4): 427-428. Cunningham, A. B. (1993): African Medicinal Plants: setting priorities at the interface between 
conservation and primary health care. Working paper 1. UNE SCO, Paris; 221pp.

Diagne, K., Zech, J., Dan, P. and Kalumiya, K. (2016): Central African Republic, regional refugee response plan at a glance.

Djerassem, M. (2016) : Rapport inter-agences sur la situation des refugies centrafricains, Portail régional sur la RCA.

Djerassem, M., Kabami, K. and Raïssa, T. N. (2016): UNHCR Factsheet | Cameroon.

Engdahl, S. (2016): WFP Cameroon Country Brief, www.wfp.org/ countries/ cameroon.

FAO, 1983: World Food security: a reappraisal of the concepts and approaches. Director General's Report. Rome.

Fokunang, C. N.; Ndikum, V.; Tabi, O. Y.; Jiofack, R. B.; Ngameni, B.; Guedje, N. M.; TembeFokunang, E. et al. (2011): Traditional Medicine: past, present and future research and development prospects and integration in the national health system of Cameroon. Afr J Tradit Complement Altem Med 8(3):284-295.

Grosse N.R. and Harkavy O., 1980: The role of health in the development. Social Science \& Medicine. Part C: Medical economics 14(2): $165=169$.

Hansch, S. and Burkholder, B. (1996): When chaos reigns: Responding to complex emergencies. Harvard Intemational Review 18(4): 10-11, 53-54.

Henderson, S. and Kendall, E. (2011): 'Culturally and linguistically diverse peoples' knowledge of accessibility and utilization of health services: Exploring the need for improvement in health service delivery'. Australian Jarmal of Primary Helth 17: 195- 201.
Hiegel, J. P. (1994). 'Use of indigenous concepts and healers in the care of refugees: Some experiences from the Thai border camps'. In A.J. Marcella (Ed.) Amidst Peril and Pain: the Mental Health and Well-being of the World's Refugees. Washington: American Psychological Association.

Hinton, D., Hinton, S., Pham, T., Chau, H. and Tran, M. (2003): 'Hit by the wind' and temperature-shift panic among Vietnamese refugees. Transaltural Psychiatry 40: 342-376.

Houghton, P.J. (1995): The role of Plants in Traditional Medicine and current therapy. J. Altem. Complem Med.1: 131-143.

Jiofack, R., Fokunang, C., Kemeuze, V., Fongnzossie, E., Tsabang, N. R., Mapongmetsem, P. and Nkongmeneck, B. A. (2008): Ethnobotany and phytopharmacopoea of the South-West ethnoecological region of Cameroon. J. Med. Plants Res 2(8):197-206.

Jiofack, T., Ayissi, I., Fokunang, C., Guedje, N. and Kemeuze, V. (2009): E thnobotany and phytomedicine of the upper Nyong valley forest in Cameroon. Afric J. Pham Phamad. 3(4): 144150.

LeBeau, D. (1998) Urban patients' utilisation of traditional medicine: upholding culture and Tradition, University of Namibia, Sociology D epartment Windhoek, Namibia, Commission Report vol 11, 33p.

Mbuli, R. (2013): Humanitarian Crises and the Management of Refugee Displacements and Integration in Central Africa: A Case Study of Cameroon. Action for Peace and Development (ASSO PED)

MINSANTE.Cameroon (2007): Conference for the midterm review of the decade on African 
traditional medicine, 2001-2010: In Plan Stratégique pour l'intégration de Medicine Traditionelle dans le système national de la santé au Cameroun $155 \mathrm{p}$.

Mollica, R. F., Cardozo, B. L., O sofsky, H. J., Raphael, B., Ager, A. and Salama, P. (2004): Mental health in complex emergencies. Lancet 364(9450): 2058-67.

Ndembiyembe, B. (1980): L'insuffisance des secours apportés aux réfugies Tchadiens est évidente. Cameroon Tribune, the National Bilingual Daily (1794): 3.

Nkongmeneck, B. A., Mapongmetsem, P. M., Pinta, Y. V., Nkuinkeu, R., Tsabang, N., Fongnzossie, E., Kemeuze, V. et al. (2007): Etat des lieux des plantes médicinales importantes à conserver et des jardins de plantes médicinales à promouvoir. Rapport CEN/ OMS/ MEM. p. 24.

Nkuinkeu, R., A saha, S. and Sakwe, C. (2007): Use and sustainable development of traditional medicine for the Littoral humid evergreen forest Ethno-Ecological region of Cameroon. CEN Report p.32.

Russell, S. S. (2002): Refugees: Risks and Challenges Worldwide. The online Jaumal of the Migation Pdice Institute

Sachedina, H. (2003): The Use of Traditional Medicine by Refugees in East Africa.

Simmelink, J., Lightfoot, E., Dube, A., Blevins, J. and Lum, T. (2013): Understanding the health beliefs and practices of East African refugees. AmJ Helth Behav. Mar; 37(2):155-61.

Singer, J. and Adams, J. (2011): The place of complementary therapies in an integrated model of refugee health care: Counselors' and refugee clients' perspectives. Journal of Refugee Studies 24(2): 351-375.

Teklehaymanot, T. (2009): Ethnobotanical study of knowledge and medicinal plants use by the people in Dek Island in Ethiopia. J. Ethnophamacd.124 (1):69-78.

Trauma Center (2016) : Rapport du Suivi et Evaluation: "Profilage des victimes de torture du Trauma Centre Cameroun".

UNHCR (United Nations High Commissioner for Refugees). (2004): Protracted refugee situations. 30th Meeting of the Executive Committee of the High Commissioner's Programme (EC/ 54/ SC/ CRP.14); Geneva, Switzerland.

UNHCR Cameroon Factsheet July 2018.

UNHCR G lobal Report Cameroon (2009). 19 pp.

WFP Cameroon country brief, March 2018

WHO ; UNICEF; UNFPA and The World Bank. (2010): Trends in maternal mortality: 1990 2008. 